\title{
Iron supplements for preterm or low birthweight infants
}

\author{
S M BARCLAY, D J LLOYD, P DUFFTY, AND P J AGGETT \\ Department of Child Health, University of Aberdeen
}

SUMMARY A survey of 57 neonatal units in the United Kingdom showed considerable disparity in iron supplementation policies for preterm low birthweight infants.

The 'ideal' intake of iron for low birthweight infants has not been established. To determine the variation in policies for iron supplementation we investigated current practices for supplementation of low birthweight infants in some neonatal units in the United Kingdom.

\section{Methods}

One neonatal unit from each regional health authority and all units attached to medical schools in the United Kingdom ${ }^{1}$ were questioned about their policy on iron supplementation for low birthweight and preterm infants.

\section{Results}

Fifty seven units ( $80 \%$ of those approached) responded: 31 from teaching hospitals and 26 from district general hospitals. Four units, all from teaching hospitals, gave no routine supplements, otherwise there were no differences in the policies of teaching and non-teaching centres.

\section{SELECTION}

In 28 units gestational age was the criterion for supplementation: 22 units supplemented infants of less than 36 weeks' gestation, four selected those below 35 weeks, and one each used gestations of less than 34 weeks and 32 weeks. Thirteen units used birth weight as the criterion, with a variety of thresholds from $1500 \mathrm{~g}$ to $2500 \mathrm{~g}$. Eleven units used a combination of these age and weight criteria. One unit supplemented every infant admitted to it.

\section{TIME OF STARTING}

Three units began supplements at 14 days postnatal age, 11 at 21 days, 24 at 28 days, nine at 42 days, and two units waited until eight and 10 weeks respec-

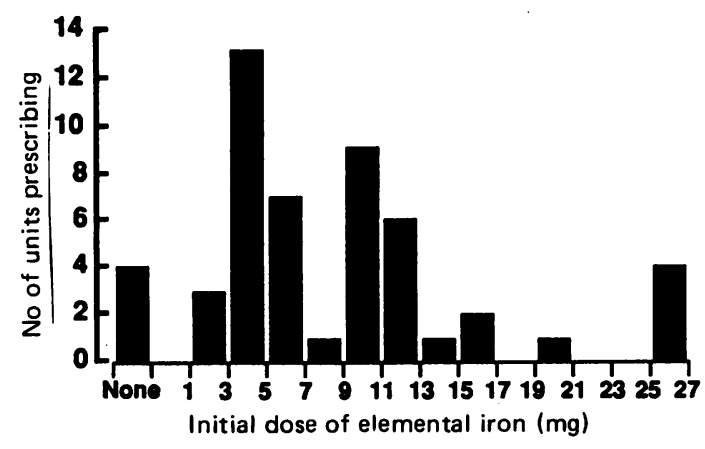

Figure Initial dose of elemental iron prescribed (1 $\mathrm{mg}=18$ umol of iron).

tively. Criteria such as achieving feeds every four hours or a postconceptional age of 36 weeks were used by three units. One centre introduced extra iron at 14 days in infants of birth weight greater than $1200 \mathrm{~g}$ and at 28 days in lighter infants.

DOSE

Forty seven units prescribed a constant dose of iron irrespective of the weight or postconceptional age of eligible infants (figure); there was a nine fold variation in dose among these units (54-4923 $\mu \mathrm{mol}$ daily).

Of six units not shown in the figure, one adjusted the dose according to postnatal age and five according to body weight, either from the onset of supplementation or at discharge. These doses ranged from 16-107 $\mu \mathrm{mol} / \mathrm{kg} /$ day.

There was no difference in the time of introducing supplements between units using higher or lower doses.

\section{DURATION}

Twenty one units advised that supplements should be continued until 6 months, and six until at least 1 year of age. Nineteen units recommended supplementation until the introduction of 'mixed feeds' or until the infants were 'fully weaned'. These latter terms were not defined. Most units thought that supplements were continued until around 6 months of age. Other criteria for stopping extra iron 
included reaching postconceptional ages ranging from 40 to 48 weeks or discharge.

Many units stressed that they were not able to verify whether their advice was being followed in the community.

\section{IRON PREPARATIONS}

Twenty four units used sodium ironedetate; nine prescribed polysaccharide-iron complex; eight ferrous sulphate; six ferrous fumarate; three ferrous succinate; two ferrous glycine sulphate, and one unit used ferric ammonium citrate.

\section{Discussion}

Despite the difficulties of formulating a policy for such a heterogeneous group, expert committees have produced similar recommendations for routine iron supplementation of low birthweight and preterm infants which at least provide a reference for practice. ${ }^{2}$ None the less there is considerable variation in such practices among neonatal units in the United Kingdom.

Low birthweight infants depend on dietary iron because of their limited iron endowment at birth and high requirements for growth. Without adequate exogenous iron, a $1000 \mathrm{~g}$ infant will become iron deficient by the time of doubling its birth weight. ${ }^{2} \mathrm{~A}$ daily intake of $36 \mu \mathrm{mol} / \mathrm{kg}$ elemental iron, however, was sufficient to prevent iron deficiency in nontransfused infants of birth weight $1000-2000 \mathrm{~g}$ who were receiving minimal dietary iron. ${ }^{3}$

During the changes of iron and haemoglobin metabolism of the first six to eight weeks of life, iron supplementation may not be needed ${ }^{2}$; furthermore at this time significant extra iron may be obtained from blood transfusions. Two units who prescribe no routine iron supplements maintain haemoglobin concentrations with transfusions.

A total daily iron intake, from all sources, of 36$54 \mu \mathrm{mol} / \mathrm{kg}$, with a maximum of $270 \mu \mathrm{mol}$ elemental iron has been recommended for low birthweight infants, by 6-8 weeks of age.

Human milk alone, despite the more efficient absorption of its iron ${ }^{5}$ cannot meet these recommendations, but iron fortified formulas may do so thereby obviating any need for supplements.
However only four units commented that their supplementation policies differentiated between breast fed and formula fed infants.

At least seven units give more than the recommended upper limit of iron, ${ }^{2}$ and some exceed the supplement $(72 \mu \mathrm{mol} / \mathrm{kg} /$ day $)$ advocated by Siimes and Jarvenpaa. ${ }^{6}$

Thus taking the extremes of feeding and supplementation practice, the total iron intakes of an infant weighing $1500 \mathrm{~g}$ at birth could range from 0.3 to $20.1 \mathrm{mmol}$ during the first two months of life. Postponing the introduction of supplements until 68 weeks of age and adjusting the dose according to body weight may avoid the theoretical risk of iron overload, but may cause difficulties in implementation, particularly after discharge. As mixed feeding may not provide adequate iron until $12-15$ months of age it is suggested that supplements may be required until this time. ${ }^{2}$

Detailed evaluation of these different policies with more prolonged infant follow up would be needed before the clinical implications of this variability in iron supplementation are known.

We thank the units who helped in this survey, and the Grampian Area Health Board Medical Endowment Funds, and Nutricia for financial support.

\section{References}

1 The directory of emergency and special care units. St Ives, Cambridgeshire: CMA Medical Data Ltd, 1987.

2 Wharton BA, chairman. Iron. Nutrition and feeding of preterm infants. Oxford: Blackwell Scientific Publications, 1987:133-42.

3 Lundstrom L, Siimes MA, Dallman PR. At what age does iron supplementation become necessary in low-birth-weight infants? J Pediatr 1977;91:878-83.

4 Dauncey MJ, Davies CB, Shaw JCL, Urman J. The effect of iron supplements and blood transfusion on iron absorption by low birth weight infants fed pasteurised human breast milk. Pediatr Res 1978;12:899-904.

5 Schulz-Lell G, Buss R, Oldigs H-R, Dorner K, Schaub J. Iron balances in infant nutrition. Acta Paediatr Scand 1987;76: 585-91.

- Siimes MA, Jarvenpaa A-L. Prevention of anaemia and iron deficiency in very low-birth-weight infants. $J$ Pediatr 1982;101:277-80.

Correspondence to Dr SM Barclay, Department of Child Health, Polwarth Building, University of Aberdeen; Foresterhill, Aberdeen AB9 2ZD.

Accepted 16 May 1989 